Volume 2, Number 2, 2016

\title{
Techniques for Natural Gas Physical Properties Definition for Flow Rate and Volume Metering Systems
}

\author{
Fedir Matiko ${ }^{*}$, Halyna Matiko, Vitalii Roman, Ivan Stasiuk \\ Lviv Polytechnic National University, 12 Stepan Bandera St., Lviv, 79013, Ukraine
}

(C) 2016 The Authors. Published by Lviv Polytechnic National University.

Received: November 18, 2016. Revised: December 12, 2016. Accepted: December 26, 2016.

\begin{abstract}
The results of researching the techniques for natural gas properties determination for flow rate and volume metering systems are presented in the paper. The necessity of developing techniques for calculating the isentropic exponent of natural gas for pressure up to $25 \mathrm{MPa}$ based on a simplified set of parameters of gas composition is shown. New techniques are proposed to define isentropic exponent and dynamic viscosity based on designed analytical dependence for the calculation the pseudo-critical density of natural gas, regression equation for isentropic exponent and improved equation of Dean and Steal for calculating gas dynamic viscosity for high pressure. Techniques adequacy verification is carried out relative to the arrays of calculated values of adiabatic index and viscosity obtained from high-precise equations of gas state and relative to the experimental data of viscosity and sound speed in natural gas. The techniques errors and the range of their application are defined using the verification results.
\end{abstract}

Keywords: flow rate metering; gas properties; isentropic exponent; dynamic viscosity; calculation technique; error.

\section{Definition of the problem to be solved}

Metering of natural gas flow rate and volume is carried out by metering systems based on microprocessor flowcomputers. This enables the implementation of real-time calculation of gas flow rate and volume taking into account the parameters of its physical properties.

In the most common metering systems, the parameters of natural gas physical properties are calculated in real time based on the measured values of gas pressure and temperature as well as on values of composition parameters which are previously defined and fed into computer. Accordingly, the flow rate and volume of gas are defined using the calculated values of physical properties and measured values of flow parameters. In such metering systems the calculating algorithms should be based on the precise techniques for calculating physical properties, particularly compressibility factor (density at operating conditions), isentropic exponent and viscosity of natural gas [1].

\section{Analysis of the recent publications and research works on the problem}

The state equations are the basis for calculating the gas mixture parameters, particularly of natural gas, and show the dependence between the compressibility factor and mixture state parameters. A large number of techniques are proposed to calculate the physical properties of hydrocarbon mixtures, particularly of natural gas. They are based on the principle of corresponding states, on the virial state equation and on special multi-constant state equations. The standards GOST 30319.1-3 96 [2-4], DSTU ISO 12213-2,3: 2009 [5, 6], ISO 20765-1: 2005 [7] are built on the basis of methods for defining physical properties of known world research centers.

It should be mentioned that the standards $[5,6,7]$ describe the methods for calculating the compressibility factor and do not consider compressibility coefficient, although it is used at equations implemented in the metering systems. The methods of standards [5] and [6] use complex iterative algorithm, the input data for the method

\footnotetext{
"Corresponding author. Email address: fmatiko@gmail.com
} 
SGERG-88 in standard [6], significantly differs from the data set for the methods used in the other normative documents in force in Ukraine. It is also necessary to define the combustion heat of natural gas in order to prepare the specified data set.

Only modified standards NX19 and GERG-91 [3] provide the possibility of calculation natural gas compressibility coefficient on the basis of simplified data on gas composition (most of flow-computers and correctors use such data set). However, these methods cannot be used for pressure values more than $12 \mathrm{MPa}$ so they cannot be applied in a number of gas metering problems, particularly for gas metering at automobile gas filling stations during its processing at high pressure. Therefore the authors developed a simplified technique for definition the compressibility coefficient within the range of pressure up to $25 \mathrm{MPa}$ which is the base of the document DSSDD 42002 [8]. This technique allows us to calculate the compressibility coefficient using a simplified data on gas composition (density at standard conditions, nitrogen and carbon dioxide contents).

A number of methods are proposed in [9] to calculate the isentropic exponent and viscosity. Methods for calculating the viscosity and the experimental data of gas mixtures viscosity are presented in [10]. However, presented equations and methods have common disadvantage - considerable error of defining the isentropic exponent and viscosity for complex hydrocarbon mixtures (particularly natural gas).

The standard [7] presents high-precise methods for calculating the isentropic exponent and the standard [4] methods for calculating natural gas isentropic exponent and viscosity. The equation for calculating the properties of 18 major technical gases, including 8 hydrocarbons and their mixtures are proposed at the technique [11]. The technique has a broad field of application and covers ranges of mixtures parameters for many problems of industrial flow metering. Document [12] provides methods for determining properties of hydrocarbon mixtures with a high content of "heavy" components and moisture. The disadvantage of the methods presented in $[4,7,11,12]$ due to their application for flow computers at the metering systems is the necessity of entering complete component composition of gas mixture. This approach requires improving the software of most flow computers and correctors used in Ukraine.

Therefore, it is necessary to develop the techniques for calculating natural gas isentropic exponent and viscosity that could be used for a wide pressure range based on the simplified data on gas composition in order to provide regulatory support of metering systems on the basis of method of variable differential pressure.

\section{Formulation of the goal of the paper}

The goal of this paper is to develop the techniques for defining isentropic exponent and dynamic viscosity of natural gas in order to calculate these parameters using simplified data on gas composition in a wide range of gas pressure and temperature.

\section{Presentation and discussion of the research results}

\subsection{Development of technique for calculating natural gas isentropic exponent}

Isentropic exponent is the parameter that should be calculated for defining natural gas flow rate using variable differential pressure method. The expansion coefficient $\varepsilon$ of gas flow is calculated using isentropic exponent $\kappa$ at flow rate equation due to this method.

The technique for calculating the isentropic exponent (TCI) is developed by the authors on the basis of principle of corresponding states. Basic equation of the technique describes the dependence of natural gas isentropic exponent on its reduced temperature and density. This regression equation is obtained using arrays of values of methane isentropic exponent [13] and values of natural gas isentropic exponent calculated on the basis of AGA8-92DC [3] for such range of parameters:

$$
\left\{\begin{array}{l}
0,1 M P a \leq p \leq 25,0 M P a \\
250 K \leq T \leq 320 K .
\end{array}\right.
$$

The basic equation for calculating natural gas isentropic exponent $\kappa$ is 


$$
\kappa=a_{1} \rho_{r}^{a_{2}}+a_{3}
$$

where $\rho_{r}$ is reduced density; $a_{1}, a_{2}, a_{3}$ are equation coefficients which depend on reduced temperature and should be calculated by the formulas:

$$
\begin{aligned}
& a_{1}=-3.3361 T_{r}^{3}+15.5399 T_{r}^{2}-24.6392 T_{r}+14.2369 ; \\
& a_{2}=-0.7697 T_{r}^{2}+1.1503 T_{r}+2.3493 \\
& a_{3}=0.6401 T_{r}^{3}-3.0926 T_{r}^{2}+4.8832 T_{r}-1.2035 .
\end{aligned}
$$

Reduced density $\rho_{r}$ and temperature $T_{r}$ should be determined by known formulas

$$
\rho_{r}=\rho / \rho_{P C}, T_{r}=T / T_{P C},
$$

where $\rho$ is density at operating conditions, $\mathrm{kg} / \mathrm{m}^{3} ; T$ is absolute temperature of gas, $\mathrm{K} ; \rho_{P C}$ is pseudo-critical density, $\mathrm{kg} / \mathrm{m}^{3} ; T_{P C}$ is pseudo-critical temperature, $\mathrm{K}$.

Pseudo-critical temperature of gas can be calculated by the formula (49) of GOST 30319.1 [2]. Pseudo-critical density should be calculated by the formula proposed by the authors for three-component mixture "methane - nitrogen - carbon dioxide" and adjusted using high-precise calculated data on isentropic exponent of natural gas of different compositions:

$$
\rho_{P C}=163.5 \cdot\left(\rho_{S T} / 0.6682\right)^{0,6}+62.62 x_{a}+163.359 x_{y},
$$

where $\rho_{S T}$ is natural gas density at standard conditions, $\mathrm{kg} / \mathrm{m}^{3} ; x_{a}$ is molar fraction of nitrogen; $x_{y}$ is molar fraction of carbon dioxide.

Natural gas density at operating conditions should be calculated by the known dependence

$$
\rho=\frac{p \cdot T_{S T}}{P_{S T} \cdot T \cdot K} \rho_{S T}
$$

where $p$ is natural gas absolute pressure, $\mathrm{MPa} ; P_{S T}, T_{S T}$ are pressure and temperature at standard conditions $\left(P_{S T}=\right.$ $\left.0.101325 \mathrm{MPa}, T_{S T}=293.15 \mathrm{~K}\right) ; K$ is natural gas compressibility coefficient.

Natural gas compressibility coefficient can be calculated within the range of parameters (1) using simplified data on the gas composition $\left(\rho_{S T}, x_{a}, x_{y}\right)$ by technique [8] which is developed by the authors. The compressibility coefficient calculation error by technique [8] within the range of parameters (1) for natural gases with density at standard conditions $\rho_{S T}=0.6673 \div 0.72 \mathrm{~kg} / \mathrm{m}^{3}$ is $\delta_{m} \leq 0.13 \%$.

The technique [8] is based on the equation

$$
K=\sum_{i=0}^{3} \sum_{j=0}^{9} a_{i j} P_{r}^{j} \cdot T_{r}^{i}
$$

where $P_{r}$ is reduced pressure, $\mathrm{MPa} ; T_{r}$ is reduced temperature, $\mathrm{K} ; a_{i j}$ are equation coefficients. The values of coefficients $a_{i j}$ and the dependences for calculation the reduced pressure and temperature are given in [8].

The isentropic exponent values were defined by TCI and were compared to the isentropic exponent values calculated by the high-precise equations $[3,4,7,14]$ in order to determine the relative error of this technique. The values of sound speed in natural gas were calculated by the formula (31) of GOST 30319.1-96 [2] based on the 
isentropic exponent values of TCI and were compared to the experimental values of sound speed in natural gas [11] and calculated values of sound speed in methane [12].

Calculated values of natural gas isentropic exponent for developing and testing of techniques within the pressure range up to $25 \mathrm{MPa}$ are defined by known thermodynamic dependencies which were modified by the authors for calculating isentropic exponent based on state equation of $Z=f(\rho, T)$ :

$$
\begin{gathered}
\kappa=Z \frac{C_{p}}{C_{V}} /\left[Z-P\left(\frac{\partial Z}{\partial P}\right)_{T}\right], \\
C_{p}=C_{p_{0}}-R T \int_{p_{0}}^{p}\left[\left(\frac{\partial^{2} Z}{\partial T^{2}}\right)_{P} T+2\left(\frac{\partial Z}{\partial T}\right)_{P}\right] \frac{d P}{P}, \\
C_{V}=C_{p}-R \cdot \frac{\left[Z+T\left(\frac{\partial Z}{\partial T}\right)_{P}\right]}{\left[Z-P\left(\frac{\partial Z}{\partial P}\right)_{T}\right]},
\end{gathered}
$$

where $C_{p}, C_{V}$ are specific heat capacities of natural gas at constant pressure and constant volume respectively, $R$ is universal gas constant, $R=8.314472 \mathrm{~kJ} /(\mathrm{kmol} \cdot \mathrm{K}) ; Z$ is compressibility factor of gas; $P, T$ are absolute pressure and temperature of gas.

Thereby, the isentropic exponent was defined by dependencies (10)-(12) for which the compressibility factor was calculated by the state equation of AGA8-92DC [3] and the values of the partial derivatives of the compressibility factor were calculated by numerical differentiation of equation AGA8-92DC. This approach is used in [14] to calculate the values of the isentropic exponent using state equation of BSB-44.

In standards $[4,7]$ the isentropic exponent is defined by analytical dependencies based on state equations, so the calculation of isentropic exponent by these standards is made without the dependencies (10)-(12).

Therefore, the verification of designed technique is carried out with respect to:

- isentropic exponent values of natural gases of different composition calculated by dependencies (10)-(12) and state equation of AGA8-92DC [3] within the pressure range from 0.1 to $25 \mathrm{MPa}$;

- isentropic exponent values of natural gases of different composition calculated by ISO 20765-1: 2005 [7] within the pressure range from 0.1 to $25 \mathrm{MPa}$;

- method VNITS SMV [4] for calculating isentropic exponent within the pressure range from 0.1 to $12.0 \mathrm{MPa}$;

- isentropic exponent values of natural gases calculated by equation of BVR-44 within the pressure range from

0.1 to $8.0 \mathrm{MPa}[14]$;

- comparing the sound speed in natural gas calculated by formula (31) of GOST 30319.1-96 [2] based on the isentropic exponent values calculated by the developed technique to the experimental values of sound speed in natural gas [15] and calculated values of sound speed in methane [16].

The relative deviation of technique value from the exact value of isentropic exponent for each point is calculated by the formula

$$
\delta=\left(\kappa_{m}-\kappa\right) / \kappa \cdot 100 \%,
$$

where $\kappa_{m}$ is the value of isentropic exponent by TCI; $\kappa$ is the high-precise value of isentropic exponent.

Verification results are presented as a diagram of the relative deviation values $\delta$ of TCI versus temperature for fixed pressure (see. Fig. 1) and the relative deviation $\delta$ versus pressure for fixed temperature (see. Fig. 2 and 3). Curves $\delta$ for each temperature on Fig. 2, 3 are marked using the following symbols:

$$
\begin{aligned}
& \text { о }-250 \mathrm{~K}, \Delta-260 \mathrm{~K}, \quad \times-270 \mathrm{~K}, \quad+-280 \mathrm{~K}, \\
& \triangleleft-290 \mathrm{~K}, *-300 \mathrm{~K}, \quad \square-310 \mathrm{~K}, \quad \triangleright-320 \mathrm{~K} .
\end{aligned}
$$




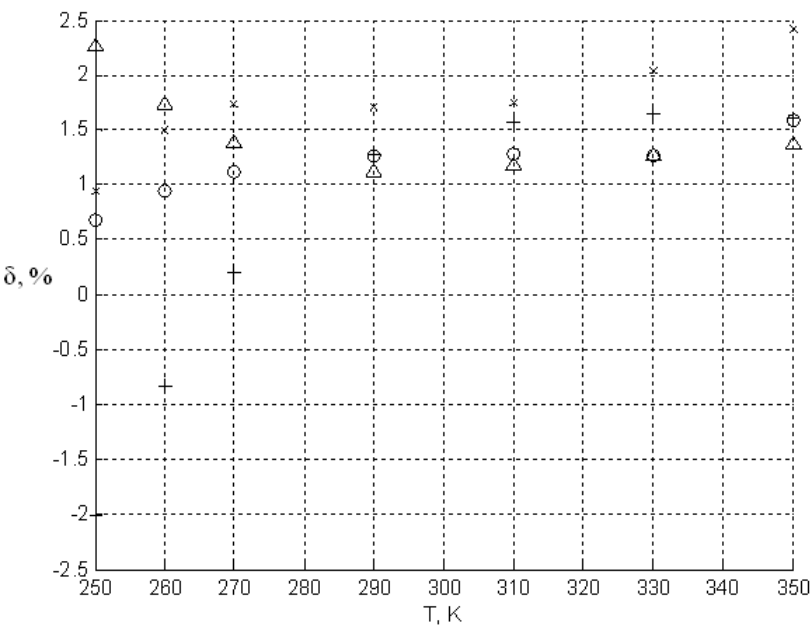

a)

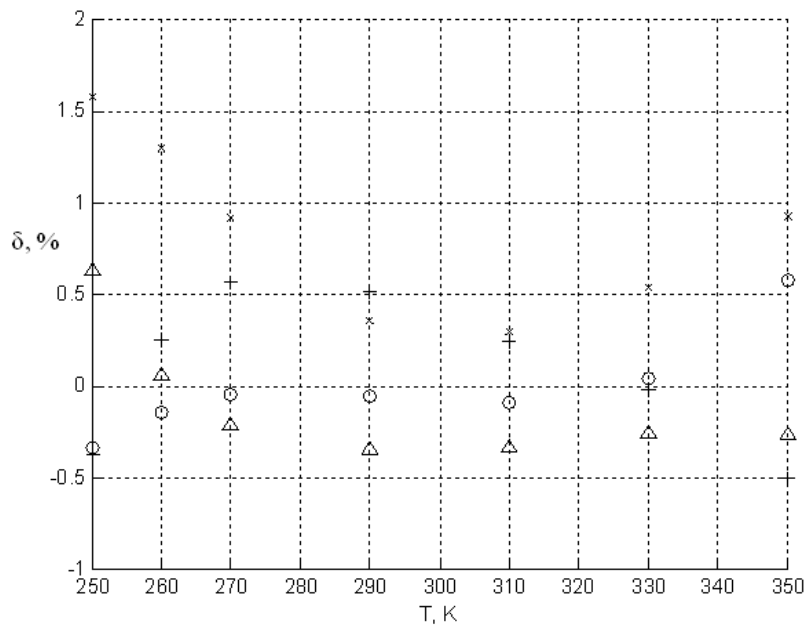

b)

Fig.1. Deviation of values of TCI from values of ISO 20765-1:2005 [7]:

a) table G.3, gas $2-\rho_{S T}=0.7320 \mathrm{~kg} / \mathrm{m}^{3}, x_{a}=3.1 \%, x_{y}=0.5 \%$;

b) table G.7, gas $6-\rho_{S T}=0.7758 \mathrm{~kg} / \mathrm{m}^{3}, x_{a}=11.7266 \%, x_{y}=1.1093 \%$;

$$
\text { o - } 5 \mathrm{MPa}, \Delta-10 \mathrm{MPa}, \times-15 \mathrm{MPa},+-20 \mathrm{MPa} \text {. }
$$

The results of comparing to isentropic exponent values of natural gases which are transported by gas transmission and distribution systems in Ukraine are decisive for defining of the technique error. The results of such comparisons are shown on the following figure. For example, Fig. 2 shows verification results relatively the method AGA8-92DC for natural gases with composition corresponding to natural gas quality certificates of „Ukrtransgaz” laboratories.

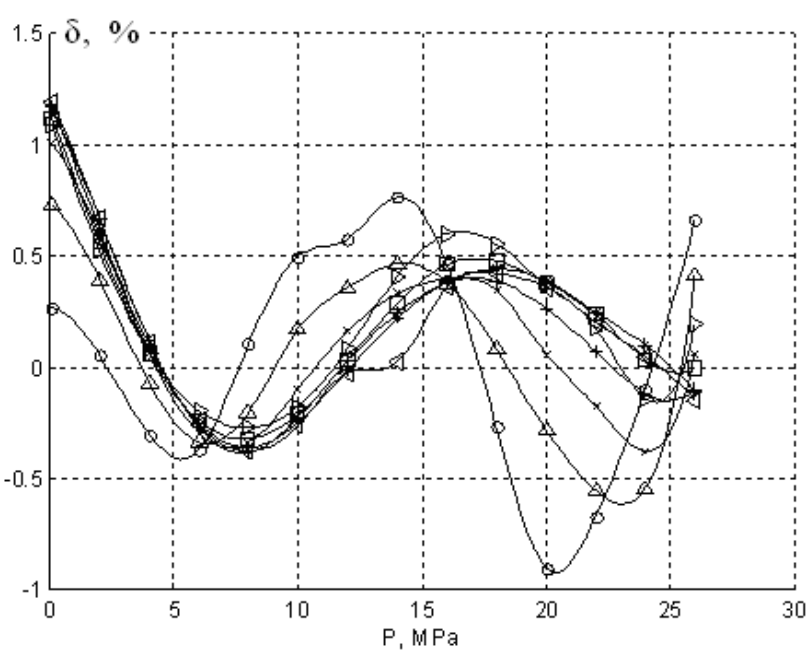

a)

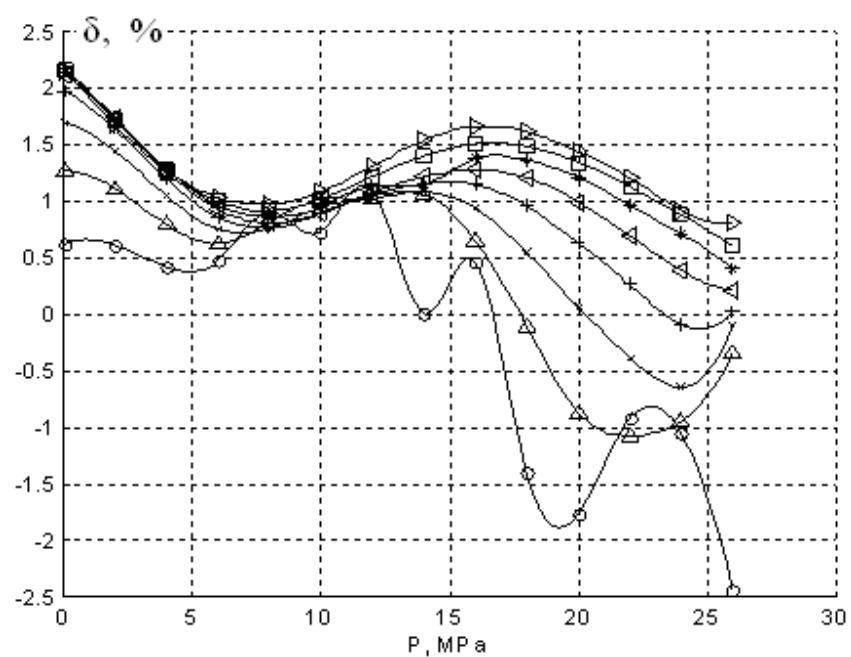

b)

Fig.2. Isotherms of deviation of values of TCI from the values of AGA8-92DC for natural gas due to quality certificates: a) GMS "Sudzha": $\rho_{S T}=0.6807 \mathrm{~kg} / \mathrm{m}^{3}, x_{a}=0.8 \%, x_{y}=0.04 \%$;

b) Krasyliv LVUMG: $\rho_{S T}=0.7195 \mathrm{~kg} / \mathrm{m}^{3}, x_{a}=0.92 \%, x_{y}=0.93 \%$; 


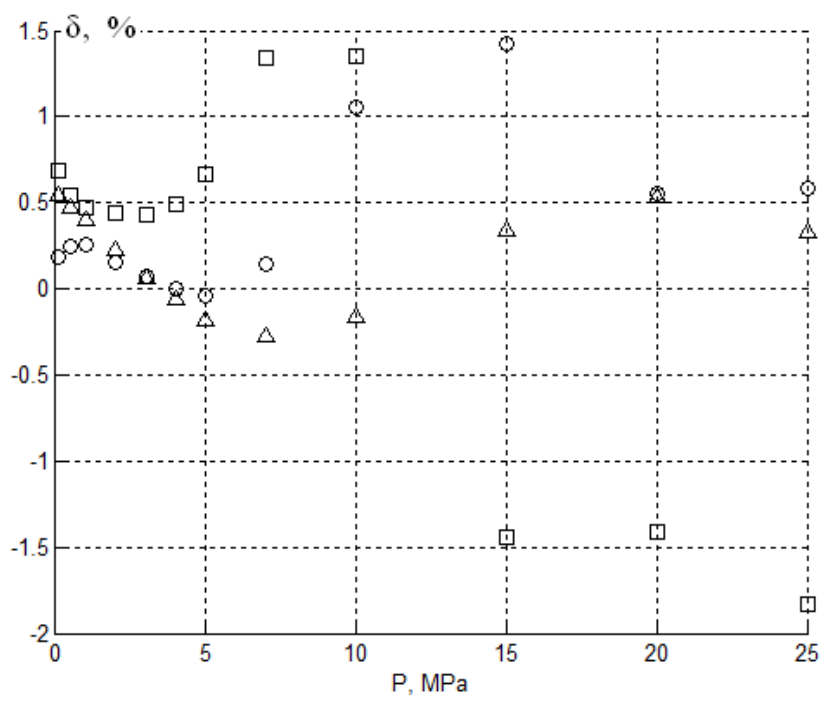

a)

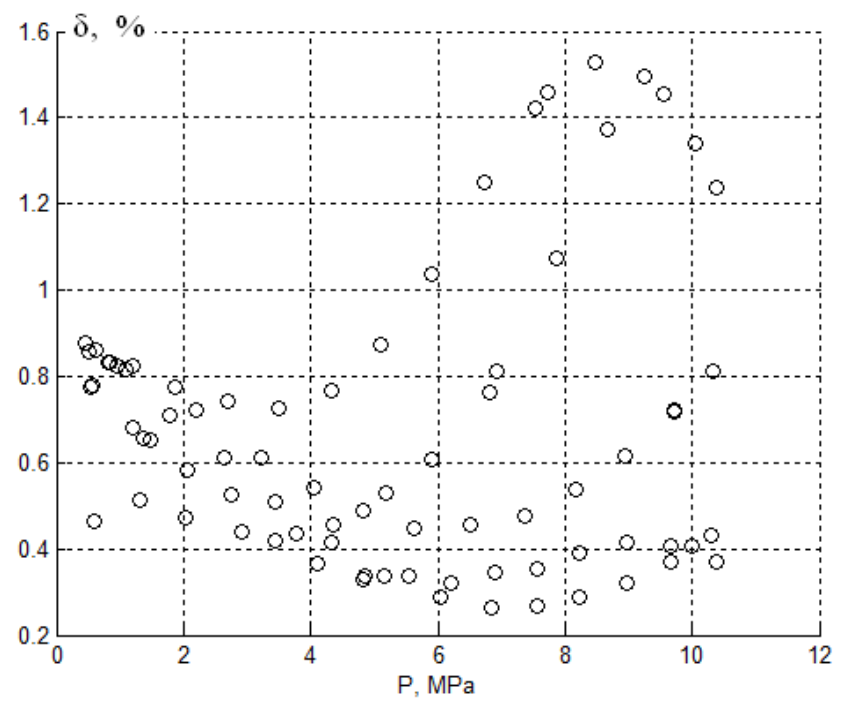

b)

Fig.3. Deviation of the sound speed calculated by isentropic exponent of TCI from the sound speed of:

a) methane [16] (o - 250 K, $\Delta-300 \mathrm{~K}, \square-350 \mathrm{~K})$;

b) natural gas GulfCoast $[15]\left(\rho_{S T}=0.69926 \mathrm{~kg} / \mathrm{m}^{3}, T=250 \div 350 \mathrm{~K}\right)$

Fig. 3 shows that the deviation of sound speed values calculated by the formula (31) [2] based on the isentropic exponent values defined by TCI from the values of sound speed of sources [11], [12] do not exceed $\pm 1.5 \%$. One point on Fig. 3, a) for $\mathrm{T}=350 \mathrm{~K}$ is an exception and is outside the range $250 \div 340 \mathrm{~K}$ specified for the technique. The deviation values do not exceed the error of technique for defining the sound speed by [2]. This fact confirms the adequacy of the developed technique for isentropic exponent defining.

Taking into account the presented testing results and the testing results relative to the other composition combinations of hydrocarbon mixtures we defined that the deviations of values calculated by TCI from isentropic exponent values obtained by state equations of AGA8-92DC [3], VNITS SMV [4], ISO 20765-1: 2005 [7], BVR-44 [14] for natural gases with density at standard conditions of $0.6682-0.725 \mathrm{~kg} / \mathrm{m}^{3}$ within pressure range from 0.1 to $25.0 \mathrm{MPa}$ and temperature range from 250 to $320 \mathrm{~K}$ do not exceed $\pm 3.0 \%$. The deviation values for technique TCI for natural gases with density at standard conditions of $0.6682-0.7 \mathrm{~kg} / \mathrm{m}^{3}$ for specified ranges of gas pressure and temperature do not exceed $\pm 2 \%$.

\subsection{Development of technique for calculating natural gas dynamic viscosity}

The technique for calculating natural gas dynamic viscosity (TCV) is developed on the basis of the principle of corresponding states. The technique is based on Dean and Steal equation [9], which is modified by the authors based on comparing of calculation results by this equation to high-precise calculated values of dynamic viscosity obtained by the method [17] within the range of parameters (1). Modified equation is

$$
\mu=\mu_{t}+\xi \cdot\left(\exp \left(1.42 \rho_{r}\right)-\exp \left(-1.11 \rho_{r}^{1,858}\right)\right)
$$

where $\mu$ is natural gas dynamic viscosity at operating pressure and temperature, $\mathrm{mcPa} \cdot \mathrm{sec} ; \mu_{t}$ is component of viscosity at low pressure, $\mathrm{mcPa} \cdot \mathrm{sec} ; \rho_{r}$ is natural gas reduced density; $\xi$ is excessive viscosity factor.

Equation (14) is based on the principle of excessive viscosity, namely natural gas viscosity is the sum of the viscosity at atmospheric pressure (temperature component) and the excessive viscosity at operating pressure that differs from atmospheric pressure. The formula from GOST 30319.1-96 [2] is applied to calculate the natural gas viscosity at pressure close to atmospheric

$$
\mu_{t}=3.24 \frac{T^{0.5}+1.37-9.09 \rho_{S T}^{0.125}}{\rho_{S T}^{0.5}+2.08-1.5\left(x_{a}+x_{y}\right)}
$$


The excessive component of viscosity at operating pressure (see (14)) is a function of reduced density, which is defined as the ratio of the density at operating conditions to pseudo-critical density (see. (6)).

The equation (7) is developed by the authors and proposed to calculate the pseudo-critical density $\rho_{P C}$ of natural gas using simplified data on gas composition (density at standard conditions, nitrogen content, carbon dioxide content).

Natural gas density $\rho$ at operating conditions is proposed to be to calculated by the known dependence (8).

The excessive viscosity factor $\xi$ is a function of pseudo-critical pressure and temperature and it is calculated by the formula [9]

$$
\xi=0,497 \frac{M^{1 / 2} P_{P C}^{2 / 3}}{T_{P C}^{1 / 6}} .
$$

where $M$ is molar mass of gas mixture, $\mathrm{kg} / \mathrm{kmol} ; P_{P C}$ is pseudo-critical pressure of gas mixture; $T_{P C}$ is pseudocritical temperature of gas mixture.

Pseudo-critical pressure $P_{P C}$ and temperature $T_{P C}$ of natural gas are proposed to be defined by the formulas (48), (49) of [2].

Molar mass of natural gas $M$ can be calculated by the formula

$$
M=\frac{\rho_{S T} R T_{S T} z_{S T}}{P_{S T} \cdot 10^{3}},
$$

where $z_{S T}$ is compressibility factor of natural gas at standard conditions.

The compressibility factor of natural gas at standard conditions $z_{S T}$ is calculated by the formula of [2]

$$
z_{S T}=1-\left(0.0741 \rho_{S T}-0.006-0.063 x_{a}-0.0575 x_{y}\right)^{2}
$$

Therefore natural gas dynamic viscosity can be calculated using analytical equations (14)-(18) and technique for calculation the compressibility coefficient [8] based on the simplified data on gas composition for gas absolute pressure from 0.1 to $25.0 \mathrm{MPa}$ and temperature from $250 \mathrm{~K}$ to $320 \mathrm{~K}$. Dependencies (14)-(18) are the base of the technique for calculating natural gas dynamic viscosity.

The adequacy verification of TCV is carried out with respect to:

- arrays of dynamic viscosity values of mixtures of different composition which are calculated by the method [17] within gas pressure range from 0.1 to $25.0 \mathrm{MPa}$;

- method VNITS SMV [4] for calculating dynamic viscosity within a range of gas pressure from $0.1 \mathrm{MPa}$ to 12.0

- $\quad$ the calculated values of methane viscosity within a pressure range from 0.1 to $25.0 \mathrm{MPa}$ [16];

- experimental values of natural gases dynamic viscosity $[10,18]$.

Some results of comparing viscosity values obtained by TCV to reference calculated values obtained by [17] and experimental values of [18] are presented as a diagram of the relative deviation $\delta$ versus pressure for fixed temperature values (see. Fig. 4, 5). The values of relative deviation are defined by the formula

$$
\delta=\frac{\mu_{m}-\mu}{\mu} \cdot 100 \%
$$

where $\mu_{m}$ is dynamic viscosity coefficient defined by TCV; $\mu$ is reference value (by methods $[4,16,17]$ and experimental values $[10,18])$.

Dependencies of relative deviation $\delta$ versus pressure for each temperature are marked by special symbol. The following symbols are used on Fig. 4:

$$
\begin{array}{cccc}
\text { o }-250 \mathrm{~K} ; & \Delta-260 \mathrm{~K} ; & \times-270 \mathrm{~K} ; & +-280 \mathrm{~K} ; \\
\triangleleft-290 \mathrm{~K} ; & *-300 \mathrm{~K} ; & \square-310 \mathrm{~K} ; &
\end{array}
$$


Comparison of the viscosity values obtained by the TCV to the standard calculated values obtained by [17] is made for some natural gases with composition that meets the quality certificate of Ukrainian gas transmission companies and some synthesized mixtures. The comparing results for two mixtures are shown on Fig. 4.

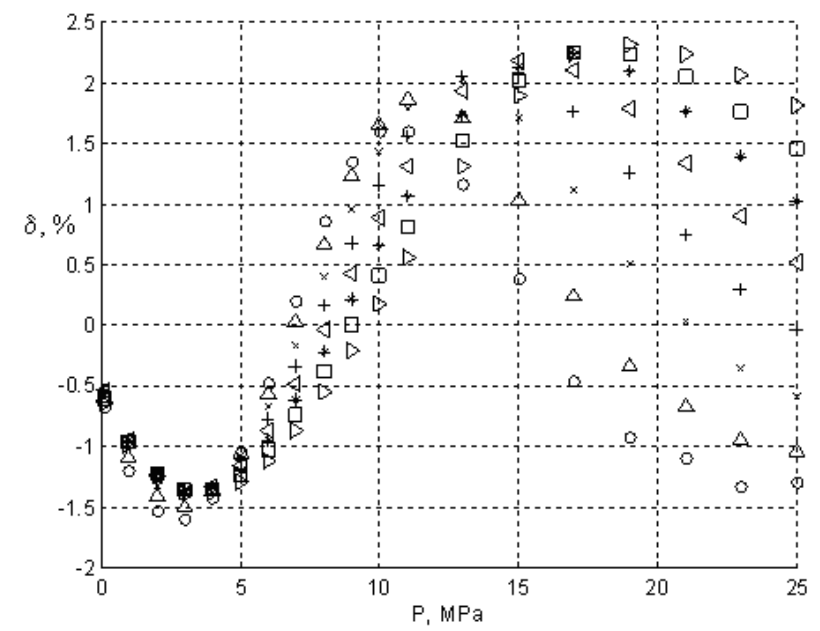

a)

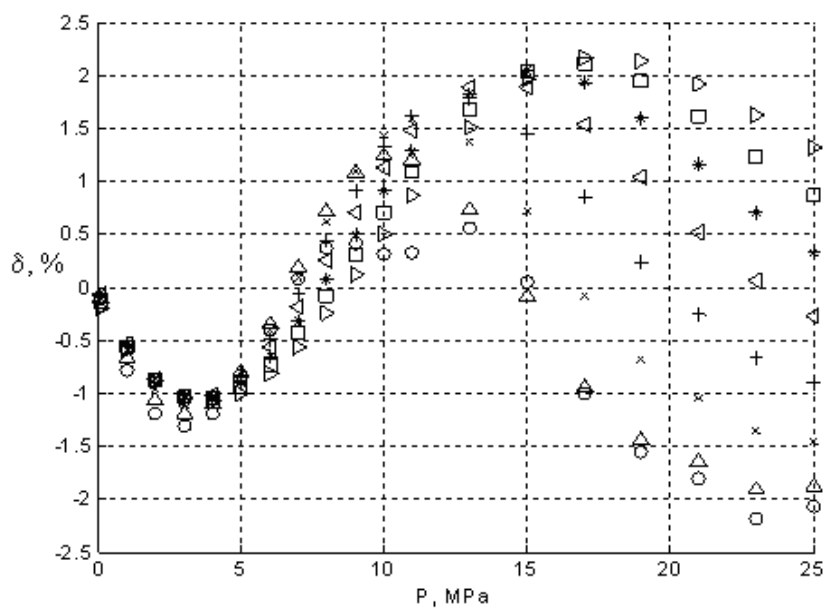

b)

Fig. 4. Relative deviation of technique values from values of method [17] for natural gas:

a) due to quality certificate of GVS Krasyliv LVU $\left(\rho_{S T}=0.7195 \mathrm{~kg} / \mathrm{m}^{3}\right)$;

b) synthesized mixture $\left(\rho_{S T}=0.7504 \mathrm{~kg} / \mathrm{m}^{3}\right)$

The detailed verification results showed that the relative deviation values of dynamic viscosity obtained by TCV from the values obtained by [17] is $-4.0 \%<\delta<3.7 \%$ for mixtures with density at standard conditions of $0.668 \mathrm{~kg} / \mathrm{m}^{3}$ to $0.75 \mathrm{~kg} / \mathrm{m}^{3}$ and nitrogen molar content of $10 \%$ and carbon dioxide molar content of $7 \%$.

It is especially important to verify the adequacy of technique relatively precise experimental values of methane dynamic viscosity [18]. The authors of the paper [18] claim that the uncertainty of the experimental viscosity values does not exceed $\pm 0.5 \%$. The relative deviation of technique values from experimental viscosity values [11] are presented on Fig. 5 for two natural gases, one of which has a high content of nitrogen and carbon dioxide. The relative deviation $\delta$ is within $-2.7 \%<\delta<0.5 \%$ (seen in Fig. 5).

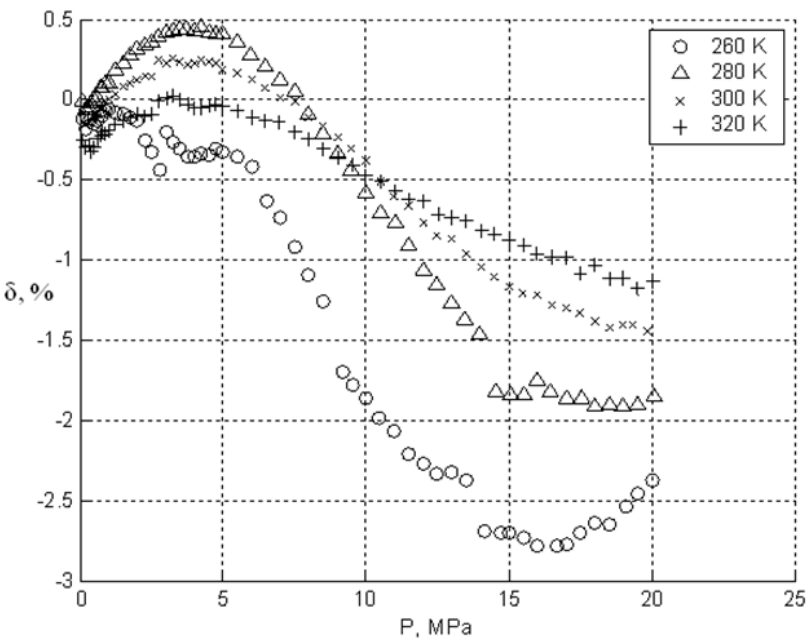

a)

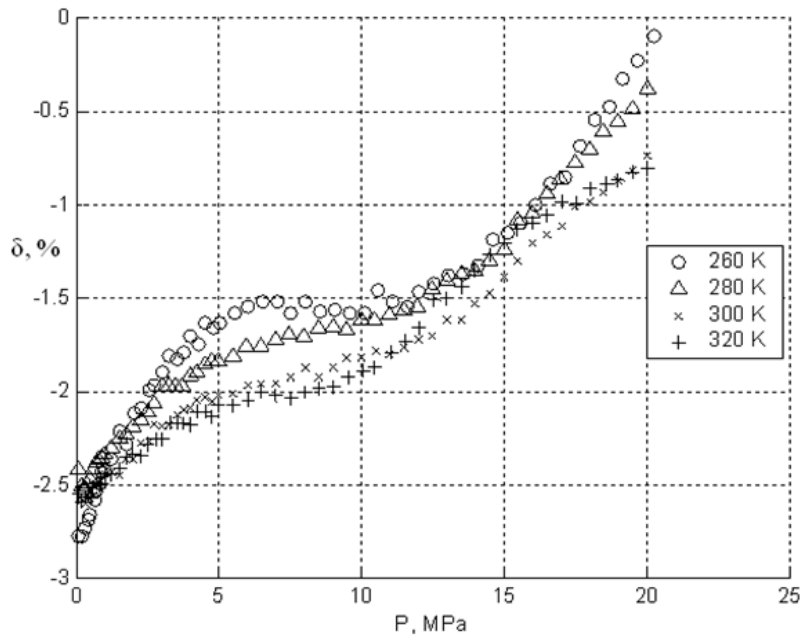

b)

Fig.5. Relative deviation values of TCV from experimental data [18] for natural gas:

a) gas $\mathrm{H}-\rho_{S T}=0.7497 \mathrm{~kg} / \mathrm{m}^{3}, x_{a}=1.5324 \% x_{y}=0.774 \%$;

b) gas L - $\rho_{S T}=0.7692 \mathrm{~kg} / \mathrm{m}^{3}, x_{a}=9.752 \% x_{y}=1.4523 \%$. 
The results of comparing viscosity values of TCV to the experimental values of natural gas viscosity of [10] show that the relative deviation is within $-1.0 \%<\delta<4.0 \%$.

Consequently the results of technique adequacy verification show that relative deviation of technique values are:

- $-1 \%<\delta<4 \%$ relatively GSSSD data [16] on methane viscosity within the pressure range from 0.1 to $25 \mathrm{MPa}$ and temperature range from $250 \mathrm{~K}$ to $350 \mathrm{~K}$;

- $4 \%<\delta<3.7 \%$ relatively the method [17] within the pressure range from 0.1 to $25 \mathrm{MPa}$ and temperature range from $250 \mathrm{~K}$ to $320 \mathrm{~K}$ for natural gas with density at standard conditions from $0.6682 \mathrm{~kg} / \mathrm{m}^{3}$ to $0.75 \mathrm{~kg} / \mathrm{m}^{3}$;

- $-3.5 \%<\delta<1.05 \%$ relatively the method VNITS SMV [4] within the pressure range from 0.1 to $12 \mathrm{MPa}$ and temperature range from $250 \mathrm{~K}$ to $320 \mathrm{~K}$ for natural gas with density at standard conditions from $0.6682 \mathrm{~kg} / \mathrm{m}^{3}$ to $0.75 \mathrm{~kg} / \mathrm{m}^{3}$;

- $-1 \%<\delta<4 \%$ relatively the experimental data [10] within the pressure range from 0.1 to $25 \mathrm{MPa}$ for natural gas with density at standard conditions $0.7288 \mathrm{~kg} / \mathrm{m}^{3}$;

- $-2.7 \%<\delta<0.5 \%$ relatively the experimental values of natural gas viscosity of [18] within the pressure range from 0.1 to $20 \mathrm{MPa}$ and temperature range from $260 \mathrm{~K}$ to $320 \mathrm{~K}$.

Hence the relative deviations of viscosity values calculated by TCV from the values of reference methods $[4,16$, 17] and experimental values of $[10,18]$ do not exceed $\pm 4 \%$ within the pressure range from 0.1 to $25 \mathrm{MPa}$ and temperature range from 250 to $320 \mathrm{~K}$ for natural gas with density at standard conditions from $0.6682 \mathrm{~kg} / \mathrm{m}^{3}$ to 0.75 $\mathrm{kg} / \mathrm{m}^{3}$, and carbon dioxide molar content of $7 \%$, nitrogen molar content of $10 \%$.

\section{Conclusion}

Verification results of both developed techniques (technique for calculating isentropic exponent and technique for calculating viscosity) show that they provide good convergence of calculated results with known high-precise methods and experimental data. Techniques enable calculating the value of isentropic exponent and dynamic viscosity coefficient for the above defined ranges of gas pressure and temperature using simplified data on gas composition (density at standard conditions, nitrogen and carbon dioxide content).

The techniques are proposed to be used for the software of computers of natural gas flow rate and volume for metering systems on the basis of variable differential pressure method and for the other flow rate metering methods.

\section{References}

[1] Matiko F. D. The impact of the uncertainties of physical properties of gaseous energy carriers for the accuracy of their metering // Measuring equipment and metrology. - 2009. - № 70. - pp. 76-81. (in Ukrainian)

[2] Natural gas. Methods for calculating physical properties. Definition of physical properties of natural gas, its components and processing products: GOST 30319.1-96. - M: Standard Publishing House, 1997. - 15 p. (in Russian)

[3] Natural gas . Methods of calculation of physical properties. Definition of compressibility coefficient: GOST 30319.2-96. - M: Standard Publishing House, 1997. - 53 p. (in Russian)

[4] Natural gas. Methods for calculating physical properties. Definition of physical properties by equation of state: GOST 30319.3-96 - M.: M: Standard Publishing House, 1996. - 27 p. (in Russian)

[5] Natural gas. Calculation of compressibility factor. Part 2. Calculation on the basis of molar composition. DSTU ISO 12213-2:2009.- K.: Derzhspozhyvstandart of Ukraine, 2009. - 32 p. (in Ukrainian)

[6] Natural gas. Calculation of compressibility factor. Part 3. Calculation on the basis of physical properties. DSTU ISO 12213-3:2009. K.: Derzhspozhyvstandart of Ukraine, 2009. - 38 p. (in Ukrainian)

[7] Natural gas - Calculation of thermodynamic properties. Part 1: Gas phase properties for transmission and distribution applications. ISO 20765-1:2005.

[8] Natural gas. Technique for calculating compressibility coefficient for pressure range of 12 ... 25 MPa: DSSDD 4-2002. - [Valid from. 01.07.2002]. - Kyiv, Derzhstandard of Ukraine, 2002. - 5 p. (in Ukrainian)

[9] Robert C. Reid, John M. Prausnitz, Thomas K. Sherwood. The properties of gases and liquids: Reference book/ Translation from English by B. I. Sokolov. - 3rd ed., Rev. and add. - L .: Chemistry, 1982. - 592 p. (in Russian)

[10] Golubiev I. F. Gas mixture viscosity. / I Golubiev, N. Hnezdilov - M.: Standard Publishing House, 1971. - 319 p. (in Russian)

[11] Calculation of density, compressibility factor, isentropic exponent and dynamic viscosity for moderately compressed gas mixtures: GSSSD MR 118-05. - M.: GNMTS "SSD", 2005. - 32 p. - (Technique GSSSD). (in Russian)

[12] Calculation of density, compressibility factor, isentropic exponent and dynamic viscosity for wet oil gas: GSSSD MR 113-03. - M.: VNITS SMV RF, 2003. - 48 p. - (Technique GSSSD). (in Russian)

[13] Thermodynamic properties of methane / Sychev V. V., Wasserman A. A., Kozlov A. D. and others. - M.: Standards Publishing House, 1979. (in Russian)

[14] Z. Kabza, B. Dobrovolsky. Analysis of influence of accuracy of defining of natural gases isentropic exponent on the error of calculation of flow rate // Thermophysical properties of substances and materials: Issue 24. Ed. Sychev V.V. - M.: Standard Publishing House, 1988. - Pp. 
141-146. (in Russian)

[15] Younglove B.A., Frederick N.V., and McCarty R.D. Speed of Sound Data and Related Models for Mixtures of Natural Gas Constituents: NIST Monograph 178. - Chicago: United States Department of Commerce, 1993. - 90 p.

[16] Liquid and gaseous methane, thermodynamic properties, dynamic viscosity and thermal conductivity for temperatures of 91-700 $\mathrm{K}$ and pressures of 0,1 ... 100 MPa. GSSSD - 195-01 / A. D. Kozlov, Yu. V. Mamonov et al. - M., 2001. - 43 p. (in Russian)

[17] Zagoruchenko V. A. Viscosity of natural gases and their main components // Thermophysical properties of substances and materials: Issue 24 - M.: Standard Publishing House, 1988. - Pp. 124-132. (in Russian)

[18] P. Schley et al. Viscosity Measurements and Predictions for Natural Gas. - International Journal of Thermophysics, Vol.25, No.6, 2004, pp.1623-1652.

\title{
Методики визначення фізичних властивостей природного газу для систем вимірювання його витрати та кількості
}

\author{
Федір Матіко, Галина Матіко, Віталій Роман, Іван Стасюк \\ Національний університет «Львівська політехніка», вул. С. Бандери 12, Львів, 79013, Украйна
}

\section{Анотація}

В статті представлено результати дослідження методів визначення властивостей природного газу, необхідних для побудови систем вимірювання його витрати та кількості. Визначено необхідність розробки методики розрахунку показника адіабати природного газу для тиску газу до 25 МПа на основі спрощеного набору параметрів складу газу. Представлено нові методики визначення показника адіабати та коефіцієнта динамічної в’язкості, розроблені авторами на основі отриманої аналітичної залежності для розрахунку псевдокритичної густини природного газу, регресійного рівняння показника адіабати та удосконаленого рівняння Діна і Стила для розрахунку динамічної в'язкості природного газу при високому тиску. Виконана перевірка адекватності методик відносно масивів розрахункових значень показника адіабати та в'язкості, отриманих на основі високоточних рівнянь стану газу, а також відносно експериментальних даних в'язкості та швидкості звуку у природному газі. За результатами перевірки визначено похибку методик та область їх застосування.

Ключові слова: вимірювання витрати; властивості газу; показник адіабати; коефіцієнт динамічної в’язкості; методика розрахунку; похибка. 